\title{
Why do patients want information if not to take part in decision making?
}

It is a central tenet of contemporary clinical ethics that patients ought to be given information about the nature of proposed treatments options, about their risks and benefits. The reason why this information ought to be given is so that patients can make their own autonomous medical decisions. To fail to give such information would constitute a lack of respect for the patient's autonomy. However, as is well known, there is evidence that many patients would be happy to defer decisionmaking to clinicians and to adopt a passive-patient-role. ${ }^{12}$ Schneider goes so far as to refer to current informed consent procedures as involving a kind of "mandatory autonomy" 3 a phenomenon described by Davies and Elwyn as the 'paradox of imposing choice on patients' ${ }^{4}$ This evidence has implications for medical ethics: do patients have a right to exempt themselves from medical decision making that pertains to them? Matters are made more complex by the fact that there is also considerable evidence that at many patients who want to defer decision-making to clinicians still want this kind of information. 567891011 As Czaja, Manfredi and Price put it: 'the desire for information and the desire for involvement in medical care are independent factors' ${ }^{12} \quad$ Auerbach concludes that 'whereas most patients say they want detailed information, far fewer say they want to participate in decision making', ${ }^{13}$ and that 'across a wide variety of medical settings, patients report that they want detailed information about their condition and their treatment whereas stated desire for input into decision making is skewed more in the direction of physician-only or at least collaborative decision-making'. ${ }^{14}$ What should the proper response to this be? Do patients have a right to information even though they don't want to make decisions themselves?

This is a complex question and we cannot hope to fully address it here. In order to even begin to address it certain hurdles have to be overcome. The first is that the evidence may be problematic for methodological reasons. Different studies use different instruments to evaluate patient preferences, with different kinds of question (some specific, some general) and different scales. ${ }^{15}$ Some ask about what the patient has done, or will intend to do, to get information; others 
simply ask about "how important" information is to the patient. Stated information preferences may not translate into action. ${ }^{16}$ Worse still, one widespread methodology for identifying decisionmaking preferences is to use hypothetical scenarios: to test what a patient would do, or prefer, in certain situations. But, as Kühberger, Schulte-Mecklenbeck and Perner note 'there is more to making decisions than considering hypothetical options' ${ }^{17}$ Similarly, Verheggen and Van Wijmen, in their study of research into informed consent to clinical trials, conclude that 'there is often a very real and marked difference between the reactions of individuals who actually have been involved in trial research and of those whose responses are based only on conjecture and supposition. ${ }^{18}$ We should thus be cautious as to how much we can infer about patients' information preferences in real, as opposed to hypothetical, decision-making contexts: especially when emotionally salient, and potentially very costly, decisions are to be made.

Auerbach concludes that 'psychometrically sound instruments' are needed if a proper evaluation of patients' informational and decisional interests is to be obtained. Auerbach's methodological critique seems well-founded and the need for methodologically more robust instruments is thus well-supported.

The second-related-problem is a lack of clarity as to why patients want information at all. The aim here is to argue that we should not be surprised that patients' desires for information should be independent of, and often stronger than, their desire to take part in decision making. Our discussion-one which uncovers a variety of reasons people may have for wanting informationalso has relevance for how empirical investigators might address some of the methodological worries raised by Auerbach and, in the final section some suggestions are made about the kinds of question that such studies might pose. This, it is hoped, will help pave the way for clearer discussion of the underlying ethical issues.

Our concern here is with why patients want information. There are two kinds of explanation we might offer. The first kind of explanation views the acquisition of information as an end in itself. 
People have an intrinsic interest in coming to know things. We read books, watch documentaries, go on trips to museums, and the like. A great deal of our knowledge-seeking may have little to do with practical decision making: learning something about rainforest animals may make no difference at all to how one behaves. In general we have a broad desire for knowledge and information that is independent of our desire to take part in decision making: so it is perhaps not surprising that, in some cases, patients want to know about treatments without taking part in decisions about them.

This first kind of explanation simply suggests that it is brute fact about human beings that we seek information. There is a second kind of explanation that is more complex, and more interesting. This kind of explanation views the acquisition of information as a means to achieving or securing

some other goal. Before offering a short list of some of these instrumental reasons, it is important to note that the items in our list are not meant to be ranked: the fact that different reasons are presented in a particular order is not meant to reflect an assumption that patients will in general find that kind of reason the most important in their deliberation and action.

\section{(i) Wanting to make decisions-but not about treatment options}

Information is extremely fecund. Any piece of information can be put to use in indefinitely many rational and practical projects. Information about treatment options may be relevant for making decisions about things other than, say, deciding which option to commit to. Suppose all treatment options have the consequence that the patient will have to stay in hospital for at least five days. The patient may have to decide who will look after her cat, given the length of the stay, even if she does not want to decide which option is best. It may be that she cannot defer decision making about the cat to another, or, it may be that she does not want to do so. We cannot directly infer from the fact that a patient does not want to take part in clinical decisions that this reflects a global preference against being involved in, or making, decisions. Because information can be used for different practical and deliberative concerns, one and the same information may be of relevance to both (a) 
an area or subject matter where the patient does not want to make decisions; (b) an area where she does. In general, it seems clear that a methodologically sound study of informational interests ought to be sensitive to which projects and decisions the information might be used for.

\section{(ii) Wanting to be psychologically and emotionally prepared}

Related to (i) is the fact that patients may want information in order to prepare themselves for the treatment, its consequences, or its risks. Some aspects of preparedness involve making decisions (as with the cat example above). But there is a broader sense of preparedness that may not: what we might think of as psychological preparedness. The patient may want to avoid having any nasty shocks or surprises. More generally, she may wish to be emotionally prepared for what might happen.

\section{(iii) Wanting to know reasons}

Giving information about treatment options and their risks plays the role of putting forward potential reasons for different kinds of action. That is, a specification of the relative risks of different courses of action can be, when coupled with other information and the patient's own goals and interests, provide reasons for favouring one course of action over another. But our interest in knowing reasons for acting extends beyond our interest in making decisions. For example, human beings have a deep interest in historical explanation: interests in why agents acted as they did even though such reasons are not going to be used in current deliberation. Such an interest is to do with understanding other agents and their actions and, although understanding others' actions may be of relevance to some of our decisions, the key point for our purpose is that we can and do desire to know why someone did some action in the past without having any desire to take part in the 
decision making that leads to this kind of action (e.g., consider our interest in understanding why a serial killer acted as he did).

The giving of reasons is such a familiar part of our everyday communication that we take it for granted. A failure or unwillingness to give reasons can be distressing, insulting or demeaning. Primo Levi tells of his experience, having arrived in Auschwitz, starved and thirsty, trying to remove an icicle so that he might drink from it. A guard takes it from him. Levi asks why. The guard replies "There is no "why?" here". ${ }^{19}$ Levi interprets this as the guard's claiming that everything is forbidden. But we can also read it as the guard's insistence that the normal game of giving reasons will not be played, so any expectation of an explanation of action will not be met. The prisoner is so contemptible that no reasons need to be given.

Suppose a patient wants to completely defer decision making to her clinician. It does not mean that she does not have an interest in learning something about the reasons for acting. In some cases this may reflect a plain interest in knowing reasons (the kind of interest that could be satisfied by knowing the reasons after the fact).

\section{(iv) Wanting respect}

Human beings have a deeply entrenched interest in being respected. Respect means many different things. For our purposes the kind of respect that is of concern is "recognition" respect (rather than the "appraisal" or "evaluative" respect that is directed at people in terms of their achievements). Respect for persons is a species of recognition respect: recognising the person as an agent, with her own distinct interest and capacities to pursue her life as she sees fit.

We have already seen that a failure to give reasons can be indicative of a lack of respect. But it would be wrong to infer that it is only when communication involves the giving of reasons that respect can be shown. Acts of informing-which are our concern here, rather than other speech acts like requesting or directing-can readily show respect, or a lack of it. 
It should be obvious that the manner of informing can show respect (or contempt). Although this is of relevance to a broader discussion of clinical communication, it is not of key concern to us here. Our concern is with the reasons that patients might have for wanting information, even though they don't want to make decisions. Our puzzling evidence does not pertain to patients preferences for how they are spoken to, but acts of informing can show respect in another way. The fact that a clinician is willing to inform a patient about treatment options may be viewed as indicative of respect (provided it is done so in respectful manner). The clinician treats the patient as someone who is capable of being informed, and who has an interest in being informed. A patient can have an interest in being respected without thereby wanting to make decisions herself. The findings by Joffe et al. support this line of thought. ${ }^{20}$ This US study sought to determine what it is that patients value in hospital care by correlating their evaluation of their care across a number of different variables with their willingness to recommend the hospital to others. The study found that the strongest correlation with a willingness to recommend was being treated with respect and dignity, and having confidence and trust in the clinicians: "These data suggest that, among the experiences measured in this survey, hospitalised patients on average value involvement in decision making less than other aspects of treatment" ${ }^{21}$

\section{(v) Wanting assurance of trustworthiness}

When we trust another to do something we rely on them to act in certain (specified) ways that respect our interests. The fact that the clinician is willing to engage in communication may help to inspire confidence in the clinician as a trustworthy agent. But how can the fact that the clinician is willing to communicate (in certain ways) provide this evidence? Onora O'Neill notes that trustworthiness with regard to some task $\mathrm{X}$ can be achieved by gaining evidence of competence with regard to some other task $Y$ (she gives the example of a King sending a suitor Prince on a long quest as a test for suitability for marriage to his daughter). ${ }^{22}$ The fact that the clinician is willing to talk in 
detail about the intervention may be taken to be a reasonable, but not infallible, basis for judging that the clinician is honest, open, and has "nothing to hide" and is likely to be trustworthy in other respects. In contrast, evasive speech, or trying to steer the patient's questions away from details, may be taken as evidence that the clinician does not give a strong consideration to the patient's interests.

\section{(vi) Wanting assurance of knowledge and competence}

One objection we might have to this line of thought is that trust always rests upon a willingness to refrain from knowing certain things: the parent who trusts the babysitter does not monitor the babysitter via a covert webcam. So, wouldn't a desire for information be indicative of a lack of trust? Once again, it is important to bear in mind that placing trust is a complex activity that must take into account at least two elements: a trustee must keep the trusting party's interests in mind (and not be swayed by self-interest when out of view of the trusting party) but she also must be competent and reliable. So, those placing trust must be able to assess, and gain assurances, that the trustee will meet both conditions. In giving information, the clinician shows herself to be knowledgeable.

There is a puzzle here though. How can a patient, who may lack medical knowledge and expertise, judge that the clinician is competent? After all, the patient may not understand what the clinician says. ${ }^{2324}$ But the mere fact that the clinician is willing to make these claims allows certain inferences to be made. Communicators know something about the risks that communication puts a speaker under: if the clinicians spouts a load of nonsense, she risks being found out (even if a patient is not expert herself, she may, for all the clinician knows, have close friends or family who are, or she may leave the consultation to consult the internet (which does raise its own problems)). So, the thought here is that receiving information from the clinician provides assurance of specific and relevant competence, and part of the rationale for this is that patients know-perhaps tacitly-that 
the clinician would not risk making explicit incorrect information, in a context where such a disclosure is likely to pose risks to her.

\section{(vii) Wanting assurance of deliberative resources}

As stressed above, these reasons for wanting information are not meant to be taken in isolation. One reason why this is so is that one and the same act of informing can provide different kinds of assurance about the clinician. In addition to competence and trustworthiness, being given information about treatment options in advance of acting may give an assurance that the clinician has resources for decision making at her disposal, with a tacit implication that she will draw upon those resources in reaching a decision. That is, prior to acting the patient has assurances that whatever treatment option is decided upon-whether it be by the patient, the clinician, or both together - it will be based upon a consideration of reasons, alternatives, risks and so on. Suppose a patient-of the kind featured in Schneider's studies-wants to entirely defer her decision making to a clinician. It is not irrational, or irrelevant to seek assurances that the decision will be made in a reasonable way, and the disclosure of information can provide this kind of assurance. That is, a patient can want to be assured that a good decision will be made (by someone else) without wanting to make that decision herself.

\section{(viii) Wanting opportunities provided by the occasion of informing}

Our discussion so far has assumed a largely passive role for the patient: patient as audience. But when information is conveyed in a face to face exchange it is standard (though not essential) that speaker and audience can interact with one another. Of particular importance is the opportunity to ask questions, to seek clarification, to check claims, and so on. If the giving of information is bound up with an opportunity to ask questions then testing a patient's interests in gaining information 
(either by asking for her information preferences or by asking her about her practices) may be testing for more than one, independent, element. That is, the patient may have been primarily interested in the opportunities provided by the occasion of informing, rather than in the content of informing.

\section{Conclusion}

What is striking from our discussion is the variety of reasons that we might have for wanting information: we might want it because its content is relevant to our decisions (other than medical ones); or, it may be that that what we want is something that the process of information-delivery shows. In some cases the fact that the information is given may be of relevance to a patient's evaluation of the clinician and the context of clinical care, in other cases the occasion of informing may provide something that is desired, once again, without the patient wanting to use the content of what is disclosed in making clinical decisions.

Our focus has been on the general question of why patients might want information. Of course, with regard to any individual patient a different kind of explanatory question can be posed, a demand for an idiographic explanation, one that pertains to the unique individual, in a specific context. Though such explanations are not the standard fare of empirical studies there is no reason why we should exclude such explanations from ethical discussions of patients informational interests. Indeed, if the discussion here is correct, there will be a complex information-seeking narrative about each individual patient's informational and decisional interests (this patient may want information to "psych herself up", that patient may want information by way of gaining a general reassurance of competence and trustworthiness).

Even without turning to specific idiographic explanations, the discussion here suggests a range of more fine-tuned questions that might be asked by way of finding out about patients informational interests in general. For example, patients could be asked which of the following they 
would prefer: meeting clinician to discuss treatment options; receiving the same information by email (though here it would be important to try to pinpoint why patients have such preferences: for example, it may be that in general we prefer face-to-face communication and, relatedly, older patients might also be suspicious or fearful of information communicated via new technologies).

For those who express a willingness to defer decision making, questions could be asked of this cohort about whether they would prefer (a) no information; (b) information prior to treatment; (c) information post-treatment. It would be interesting to find out whether the patients who do not want to make certain kinds of medical decisions, but who do want information, have a stronger, general, informational interest than others: this could be tested by asking a range of questions about other (nonmedical) intrinsic informational interests ("Do you read a lot of non-fiction?" "Do you watch news programmes? "Do you watch documentaries?"). It would be an interesting finding if it were to turn out that patients' level of informational interest was specifically to do with clinical matters whilst, at the same time, not being linked to making clinical decisions. At this point this could even prompt further direct self-explanatory questions, as part of a qualitative study, as to why such information was sought. Patients' answers may not be the last word on the matter (unless we assume that people automatically know all the reasons that there are for their actions and attitudes).

These proposed avenues of research still face the kinds of problem noted earlier (e.g., where conclusions about patients' decision-making preferences in real contexts are drawn from finding out about their responses in hypothetical situations. But, at this stage, these proposals are merely tentative suggestions, and it is hoped that the discussion here will be of use to those who seek to develop sound instruments for gaining information about patient information preferences. What should be clear from the discussion above, is that given the fecundity of information, and the complex multi-channelled nature of communication, it is no surprise at all that patients should want information about treatment options even when they want to defer decision making about such 
options to others. Whether patients have a right to such information, in the absence of wanting to take part in clinical decision-making, is a matter for another occasion.

\section{REFERENCES}

\footnotetext{
${ }^{1}$ Levinson W, Kao A, Kuby, A, et al. Not all patients want to participate in decision making.
} A national study of public preferences. J Gen Intern Med 2005;20(6):531-5.

${ }^{2}$ Schneider, C. The Practice of Autonomy: Patients, Doctors and Medical Decisions. New York: OUP, 1999.

${ }^{3}$ Schneider, C. The Practice of Autonomy: Patients, Doctors and Medical Decisions. New York: OUP, 1999 (137-180).

${ }^{4}$ Davies M and Elwyn G. Advocating Mandatory Patient 'Autonomy' in Healthcare: Adverse Reactions and Side Effects. Health Care Anal 2008;16:315-328 (324).

${ }^{5}$ Ende J, Kazis L, Ash A, et al. Measuring patients' desire for autonomy: decision making and information-seeking preferences among medical patients. J Gen Intern Med 1989;4:23-30.

${ }^{6}$ Nease RF and Brooks WB. Patient desire for information and decision making in health care decisions. J Gen Int Med 1995; 10: 593-600.

${ }^{7}$ Czaja R, Manfredi, C, Price, J. The Determinants and Consequences of Information Seeking Among Cancer Patients. Journal of Health Communication 2003; 8: 529-562.

\footnotetext{
${ }^{8}$ Rees CE, Bath PA. Information-seeking behaviors of women with breast cancer. Oncol Nurs Forum 2001;28(5):899-907.

${ }^{9}$ Deber RB, Kraetschmer N, Irvine, J. What role do patients wish to play in treatment decision making? Arch Intern Med 1996; 156: 1414-20.
} 
${ }^{10}$ Flynn KE, Smith MA, Vannness, D. A typology of preferences for participation in healthcare decision making. Soc Sci Med 2006; 63(5): 1158-1169.

${ }^{11}$ Auerbach SM. Do Patients Want Control over their Own Health Care? A Review of Measures, Findings, and Research Issues. J Health Psychol 2001; 6: 191-203 (196).

${ }^{12}$ Czaja R, Manfredi, C, Price, J. The Determinants and Consequences of Information Seeking Among Cancer Patients. Journal of Health Communication 2003; 8: 529-562 (556).

${ }^{13}$ Auerbach SM. Do Patients Want Control over their Own Health Care? A Review of Measures, Findings, and Research Issues. J Health Psychol 2001; 6: 191-203 (196).

${ }^{14}$ Auerbach SM. Do Patients Want Control over their Own Health Care? A Review of Measures, Findings, and Research Issues. J Health Psychol 2001; 6: 191-203 (191).

${ }^{15}$ Auerbach SM. Do Patients Want Control over their Own Health Care? A Review of Measures, Findings, and Research Issues. J Health Psychol 2001; 6: 191-203.

${ }^{16}$ Beisecker AE, Beisecker, TD. Patient information-seeking behaviours when communicating with doctors. Medical Care 1990; 28: 19-28.

${ }^{17}$ Kühberger, A. Schulte-Mecklenbeck,M, Perner, J. Framing decisions: Hypothetical and real. Organizational Behavior and Human Decision Processes 2002;89: 162-1175 (1163).

${ }^{18}$ Verheggenn, FWSM Van Wijmen, FCB. Informed consent in clinical trials. Health Policy.1996;36:131-153 (135).

${ }^{19}$ Levi, P. If this is a Man. Trans Stuart Woolf. London: Abacus 1975 (p. 35).

${ }^{20}$ Joffe S, Manocchia M,Weeks JC, et al. What do patients value in their hospital care? An empirical perspective on autonomy centred bioethics. J Med Ethics 2003; 29: 103-108.

${ }^{21}$ Joffe S, Manocchia M,Weeks JC, et al. What do patients value in their hospital care? An empirical perspective on autonomy centred bioethics. J Med Ethics 2003; 29: 103-108 (106). 
${ }^{22}$ O’Neill, O. A Question of Trust. Cambridge University Press, 2002 (p. 83).

${ }^{23}$ Byrne DJ, Napier, A, Cuschieri, A. How informed is signed consent? Br Med J (Clin Res Ed) $1988 ; 296: 839-840$.

${ }^{24}$ Lloyd, AJ. The extent of patients' understanding of the risk of treatments. Qual Health Care 2001; 10: 14-18. 